\title{
AÇÚCAR MASCAVO EM GELEIADAS DE MAÇÃ
}

\author{
BROWN SUGAR IN APPLE JELLIES
}

\section{Carla Rosane Mendonça ${ }^{1}$ Rosane da Silva Rodrigues ${ }^{2}$ Rui Carlos Zambiazi ${ }^{3}$}

RESUMO

O trabalho objetivou elaborar geleiadas de maçã utilizando açúcar mascavo. As geleiadas foram elaboradas com polpa de maçã, água, suco de limão, pectina e 20, 35, 50 e $65 \%$ de açúcar mascavo em relação à quantidade de polpa. Verificouse o rendimento, custo, e a preferência do consumidor pelas diferentes formulações. As geleiadas mais preferidas foram reelaboradas e determinaram-se as características físicas, químicas e microbiológicas, logo após o processamento, aos 30,60 e 90 dias de estocagem. Os resultados permitiram concluir que as geleiadas elaboradas com 35, 50 e $65 \%$ de açúcar mascavo foram igualmente preferidas pelos consumidores, superando aquela com 20\%; considerando o custo e o rendimento, verificouse que a geleiada com $65 \%$ de açúcar mascavo apresentou vantagem sobre as demais; a estabilidade desses produtos foi superior a três meses; e existiram diferenças físicas e químicas significativas entre as formulações.

Palavras-chave: açúcar mascavo, geleiada, maçã, conservação de frutas.

\section{SUMMARY}

The work had the objective to elaborate apple jellies by using brown sugar. The jellies were elaborated with apple pulp, water, lemon juice, pectin and 20,35, 50 and 65\% of brown sugar. It was verified the yield, cost and the consumer's preference of the jelly formulations. The most favorite jellies, were reprocessed, and it was determined the physical, chemical and microbiological characteristics, soon after the processing, after 30, 60 and 90 days of storage. It was observed that the jellies elaborated with 35, 50 and $65 \%$ of brown sugar were equally acceptable by the consumers, overcoming that ones with $20 \%$; the jelly with $65 \%$ of brown sugar presented advantages over the others, when considering the cost and yield; the products stability was superior to three months and there were a physical and chemical significative difference among the formulations.

Key words: brown sugar, jelly, apple, conservation of fruit.

\section{INTRODUÇÃO}

As frutas e hortaliças conservadas pela adição de açúcar estão entre os produtos mais produzidos no país, tanto industrial como artesanalmente, principalmente no sul do Rio Grande do Sul. Nesta região, é expressiva a produção e o consumo de frutas cristalizadas, geléias, doces em massa, entre outros (RODRIGUES et al., 1998).

O açúcar é componente essencial à fabricação desses produtos, sendo normalmente utilizada a sacarose na forma de cristal branco refinado (JACKIX, 1988). Entretanto, na obtenção desse açúcar, especialmente durante as etapas de extração e refino, são acrescentados alguns aditivos tais como clarificantes, antiumectantes, precipitadores e conservantes que permanecem, pelos menos em parte, nos produtos aos quais são adicionado, (BONTEMPO, 1985; VETTORAZZI \& MACDONALD, 1989).

O açúcar mascavo, ao contrário do refinado, não passa por nenhum tipo de processo de refino ou beneficiamento e, portanto, pode ser um substituto do açúcar branco na elaboração desses produtos (BONTEMPO, 1985). Comparativamente, o açúcar mascavo difere do açúcar branco, principalmente, pela sua coloração escura, e pelo menor percentual de sacarose (RODRIGUES et al., 1998). Além disso, o açúcar mascavo diminui a carga energética específica e sua composição não compromete a absorção de nutrientes pelo organismo; seu uso moderado evita obesidade, diabete, diminui sensivelmente as

\footnotetext{
${ }^{1}$ Economista Doméstica, Mestre em Ciência e Tecnologia Agroindustrial, Departamento de Ciência e Tecnologia Agroindustrial, Faculdade de Agronomia Eliseu Maciel, Universidade Federal de Pelotas (UFPEL). Endereço Particular: Rua Estevão Cândido Jorge dos Reis, 514, Centro, 96025-160, Pelotas, RS. E-mail: sidcar@ufpel.tche.br

${ }^{2}$ Engenheiro Agrônomo, Mestre em Ciência e Tecnologia Agroindustrial, Doutoranda de Ciência dos Alimentos, UNICAMP, Professor do Departamento de Ciência dos Alimentos, UFPEL.

${ }^{3}$ Químico Industrial, Doutor em Food and Nutritional Science, Professor do Departamento de Ciência dos Alimentos, UFPEL. Recebido para publicação em 07.06.99 Aprovado em 22.03.00
} 
cáries dentárias e os danos à calcificação infantil, ajudando no bom desempenho do sistema digestivo e das funções hepática e renal (IBGE, 1976; SPEARS \& KASSOUF, 1996). Assim, esse açúcar atende aos grupos de pessoas que possuem hábitos alimentares baseados na minimização ou eliminação de produtos químicos agregados.

As geléias, em geral, devem apresentar conteúdo de sólidos solúveis ( ${ }^{\circ}$ Brix) em torno de 65\% (ALBUQUERQUE, 1997), $\mathrm{pH}$ entre 3 e 4 (REIS, 1982), acidez entre 0,3 e 0,8\% (JACKIX, 1988), açúcares totais em torno de $60 \%$ (FONSECA, 1999); e de acordo com os padrões definidos pelas Normas Técnicas Especiais e Relativas a Alimentos e Bebidas anexas ao decreto $\mathrm{n}^{\circ} 12.486$ de 30 de outubro de 1978 , no máximo, $10^{2}$ NMP.g ${ }^{-1}$ de bactérias do grupo de coliformes, ausência de coliformes de origem fecal em 1 grama e no máximo $10^{3}$ UFC. ${ }^{-1}$ de mofos e leveduras (CNNPA, 1978).

Sabe-se que os produtos conservados à base de açúcar branco têm vida de prateleira de, no mínimo, um ano (SENAI-RS, 1990). No entanto, em função das características diferenciadas do açúcar mascavo, especialmente por seu maior teor de nutrientes e de umidade, e menor teor de glicídios, não se pode afirmar que os produtos elaborados com esse açúcar apresentem o mesmo comportamento.

Essas particularidades entre o açúcar branco e o açúcar mascavo podem modificar as características físicas e químicas e especialmente sensoriais, as quais são determinantes na aceitação de doces de frutas elaborados com açúcares.

Devido a esses fatores, este trabalho objetivou elaborar geleiadas de maçã utilizando açúcar mascavo em diferentes concentrações, verificar sua preferência em frente a uma equipe de julgadores, determinar o rendimento, custo, características físicas, químicas e microbiológicas dos produtos elaborados, logo após o processamento e ao longo de três meses de estocagem.

\section{MATERIAL E MÉTODOS}

O trabalho foi desenvolvido nos laboratórios do Departamento de Ciência dos Alimentos da Faculdade de Ciências Domésticas e nos laboratórios do Departamento de Química Orgânica do Instituto de Química e Geociências da Universidade Federal de Pelotas.

Materiais - Foram utilizadas maçãs da cultivar Fuji, fornecidas pela Embrapa Clima Temperado; açúcar mascavo e limão, ambos obtidos no comércio local.

Métodos - O trabalho foi realizado em duas etapas. $\mathrm{Na}$ primeira, objetivou-se avaliar o custo, o rendimento e a preferência dos consumidores por geleiadas de maçã com diferentes concentrações de açúcar mascavo. A partir dos resultados obtidos na fase inicial, partiu-se para a segunda etapa; reelaboraram-se as geleiadas mais preferidas pelos consumidores, determinando-se suas características físicas, químicas e microbiológicas, logo após o processamento e ao longo de três meses de estocagem.

As maçãs foram lavadas, descascadas e submetidas à remoção do centro em processos manuais e, após, picadas com auxílio de cortador mecânico. As cascas das maçãs foram utilizadas para extração de pectina (NEVES, 1990).

Foram elaboradas quatro diferentes formulações de geleiadas, alterando-se a proporção entre polpa de maçã e açúcar. Para elaboração das mesmas, usaram-se $20 \%$ de água, $8 \%$ de suco de limão, $5 \%$ de pectina líquida e 20, 35, 50 ou $65 \%$ de açúcar mascavo, calculados sobre o peso da fruta.

A polpa de maçã obtida, conforme descrito anteriormente, foi aquecida em tacho de alumínio aberto, juntamente com a água e a pectina líquida, por aproximadamente 30 minutos. Após este período, foram adicionados o açúcar mascavo e o suco de limão, mantendo-se sob aquecimento até atingir aproximadamente $67^{\circ} \mathrm{Brix}$.

$\mathrm{O}$ produto foi acondicionado em frascos de vidro, previamente esterilizados, com capacidade aproximada de $400 \mathrm{~g}$, os quais foram hermeticamente fechados com tampas metálicas. A pasteurização foi efetuada, colocando-se os frascos em água a $100^{\circ} \mathrm{C}$ por 20 minutos. Ao final dessa etapa, procedeu-se o resfriamento, vertendo-se água lentamente sobre os frascos, os quais foram acondicionados à temperatura ambiente.

Análises - A análise sensorial das geleiadas foi realizada através de teste de preferênciaordenação (STONE \& SIDEL, 1993), considerandose para soma de ordens valor 1 (um) para a geleiada mais preferida e valor 4 (quatro) para a geleiada menos preferida. Participaram do teste 101 julgadores não treinados, aos quais se solicitou que ordenassem as amostras da "mais preferida" até a "menos preferida". Solicitou-se que expressassem o quanto "gostaram" ou "desgostaram" dos produtos, através do uso de escala hedônica, sendo que os resultados foram expressos em \%. Ainda, a razão de sua preferência, a partir da enumeração dos atributos que influenciaram a escolha (sabor característico, cor, gosto doce, odor e textura).

O rendimento das geleiadas de maçã $(\%)$ foi calculado pela relação de peso entre a fruta e o produto final. $\mathrm{O}$ custo foi determinado considerando o preço da matéria-prima no período, na moeda corrente. 
As análises físicas e químicas realizadas nas maçãs e nas geleiadas foram efetuadas imediatamente após o processamento e aos 30, 60 e 90 dias de estocagem, seguindo os procedimentos indicados pelas Normas Analíticas do Instituto Adolfo Lutz (INSTITUTO ADOLFO LUTZ, 1985). Foram realizadas as seguintes análises: umidade, $\mathrm{pH}$, acidez, sólidos solúveis e açúcares totais, redutores e nãoredutores.

As análises microbiológicas das geleiadas foram realizadas imediatamente após o processamento e aos 30, 60 e 90 dias de estocagem. Investigou-se a possível presença de coliformes totais (NMP.g ${ }^{-1}$ ) e mofos e leveduras (UFC. ${ }^{-1}$ ), utilizando as técnicas do Bacteriological Analytical Manual for Foods (FDA, 1992).

Delineamento estatístico - O experimento foi realizado em duplicata e as análises físicas, químicas e microbiológicas em triplicata. Os resultados foram avaliados pela análise de variância (ANOVA) e os valores que mostraram diferença significativa de médias foram complementados com o teste de Duncan em nível de 5\% de probabilidade, utilizando o programa Statistica 5.1.

\section{RESULTADOS E DISCUSSÃO}

O resultado do teste de preferênciaordenação pode ser visualizado na figura 1 , sendo que o maior valor de soma de ordens demostra menor preferência dos consumidores pelo produto.

A geleiada de maçã elaborada com $20 \%$ de açúcar mascavo foi a menos preferida pelos julgadores, sendo que os demais tratamentos não mostraram diferença significativa entre si $(p<0,05)$. Os atributos que influenciaram na apreciação desses produtos pelos julgadores foram o sabor característico, o gosto doce, a cor, a textura e o odor, corres-

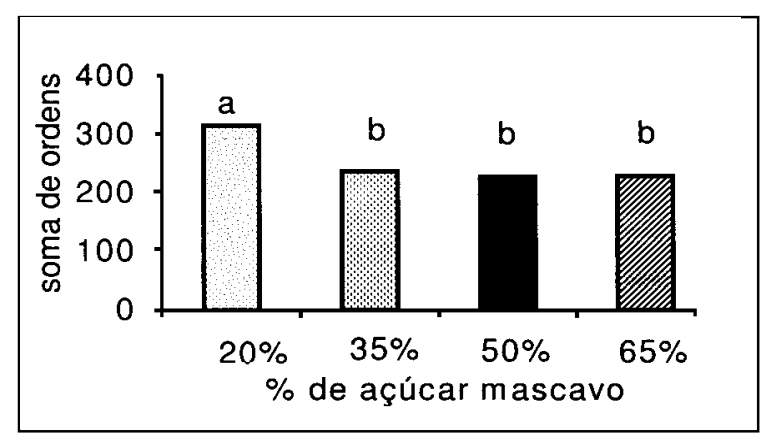

Letras diferentes nas barras representam diferença significativa pelo teste de Duncan em nível de 5\% de probabilidade.

Figura 1 - Preferência dos julgadores pelas geleiadas de maçã formuladas com 20,35, 50 e $65 \%$ de açúcar mascavo. pondente a $56,84 \%, 29,47 \%, 6,32 \%, 5,26 \%$, e $2,11 \%$ das respostas, respectivamente.

Verificou-se que a intensidade de preferência pelas geleiadas, na faixa entre "gostei muito" e "gostei ligeiramente" (Tabela 1), representou $79 \%$ das respostas dos julgadores para a geleiada com $65 \%$ de açúcar mascavo, $83 \%$ das respostas dos julgadores para geleiada com $50 \%$ de açúcar mascavo, para geleiada com $35 \%$ de açúcar mascavo $71 \%$ das respostas, enquanto que para geleiada com $20 \%$ de açúcar mascavo representou apenas 46,5\% das respostas, enfatizando os resultados do teste de preferência (Figura 1), no qual a geleiada com $20 \%$ de açúcar mascavo mostrou-se menos preferida.

O aumento do percentual de açúcar mascavo empregado na geleiada gerou uma elevação no rendimento da mesma (Figura 2).

Entre as geleiadas com 20 e $35 \%$ e as com 35 e $50 \%$ de açúcar mascavo, o acréscimo de açúcar da ordem de $15 \%$ proporcionou um incremento de peso significativo de $8,76 \%$ e $7,2 \%$, respectivamente, enquanto que o aumento de $15 \%$ de açúcar, de 50 para $65 \%$, gerou um aumento significativo de peso da ordem de $34,4 \%$.

Entretanto, o acréscimo de $15 \%$ na quantidade de açúcar mascavo gera um aumento de 4,4\% no custo do produto. Assim, considerando o custo, o rendimento e a preferência dos consumidores, verificou-se que a geleiada com $65 \%$ de açúcar mascavo apresentou vantagem sobre as demais.

Os resultados obtidos nas análises físicas e químicas das maçãs "in natura" (Tabela 2) são bastante similares aos descritos na literatura (IBGE, 1976; CHARLEY, 1982; GOULARTE, 1996), evidenciando ser uma fruta ácida e doce, constituindose em boa matéria-prima para o preparo de geléias ou geleiadas.

Tabela 1 - Intensidade de preferência (\%) dos consumidores pelas geleiadas de maçã elaboradas com 20,35, 50 e $65 \%$ de açúcar mascavo.

\begin{tabular}{lrrrr}
\hline & \multicolumn{4}{c}{$\begin{array}{c}\text { \% de Açúcar mascavo nas } \\
\text { geleiadas de maçã }\end{array}$} \\
\cline { 2 - 5 } Intensidade de preferência (\%) & 65 & 50 & 35 & 20 \\
\hline Gostei muitíssimo & 20 & 10 & 14 & 6 \\
Gostei muito & 25 & 30 & 16 & 10 \\
Gostei moderadamente & 18 & 23 & 28 & 16 \\
Gostei ligeiramente & 16 & 20 & 13 & 14 \\
Indiferente & 4 & 7 & 13 & 13 \\
Desgostei ligeiramente & 11 & 6 & 11 & 19 \\
Desgostei moderadamente & 3 & 4 & 3 & 15 \\
Desgostei muito & 2 & 0 & 1 & 4 \\
Desgostei muitíssimo & 1 & 0 & 1 & 3 \\
\hline
\end{tabular}




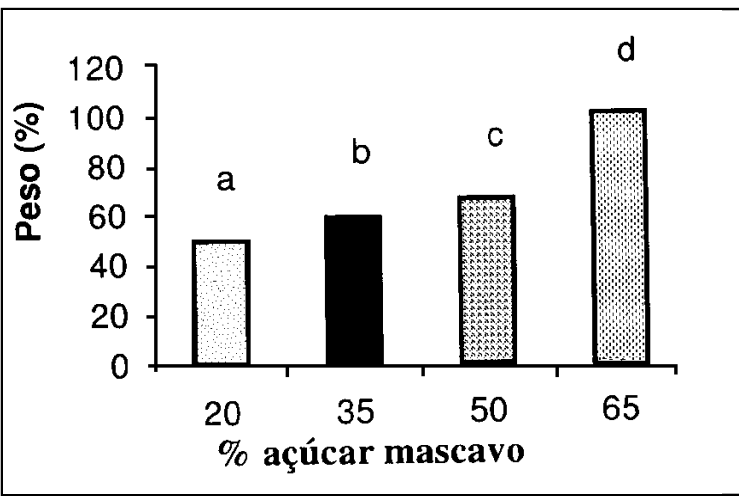

Letras diferentes nas barras representam diferença significativa pelo teste de Duncan em nível de $5 \%$ de probabilidade.

Figura 2 - Rendimento (\%) das geleiadas de maçã formuladas com $20,35,50$ e $65 \%$ de açúcar mascavo.

Entretanto, comparando-se os resultados das análises das maçãs "in natura" (Tabela 2) com os resultados obtidos nas geleiadas (Tabela 3), verificou-se que com o processamento o $\mathrm{pH}$ reduziu em função da adição de ácido cítrico, o qual proporcionou, também, o aumento da acidez. O teor de sólidos solúveis e o percentual de açúcares totais elevaramse consideravelmente devido à adição de açúcar, enquanto que a umidade reduziu bastante, em função da evaporação da água durante o tratamento térmico.

Na tabela 3, pode-se observar que durante o armazenamento por 90 dias, embora tenham ocorrido alterações significativas nas geleiadas de maçã elaboradas com 35, 50 e $65 \%$ de açúcar mascavo, os resultados das determinações físicas e químicas mantiveram-se dentro de valores aceitáveis para tais produtos (REIS, 1982; JACKIX, 1988; ALBUQUERQUE, 1997; FONSECA, 1999). Verificou-se que a formulação elaborada com $35 \%$ de açúcar mascavo não diferiu significativamente quanto a acidez ao longo dos 90 dias de estocagem

Tabela 2 - Características físicas e químicas da polpa de maçã da cultivar Fuji.

\begin{tabular}{lc}
\hline \multicolumn{1}{c}{ Determinações } & Resultados* \\
\hline $\mathrm{pH}$ & 4,28 \\
Sólidos solúveis ( ${ }^{\circ}$ Brix $)$ & 11,80 \\
Acidez (\% de ácido cítrico) & 0,17 \\
Umidade (\%) & 86,39 \\
Açúcar total (\% glicose) & 10,39 \\
Açúcar redutor (\% glicose) & 8,81 \\
Açúcar não-redutor (\% sacarose) & 1,50 \\
\hline
\end{tabular}

* Os resultados expressam a média aritmética de três repetições. e, em relação ao açúcar não redutor, não houve diferença até 60 dias de estocagem, para mesma formulação. Na formulação com $50 \%$ de açúcar mascavo, não houve alteração significativa de $\mathrm{pH}$, durante o período analisado. Constatou-se, também, a inexistência de diferença significativa para $\mathrm{pH}$ e açúcar redutor na formulação elaborada com $65 \%$ de açúcar mascavo, ao longo dos 90 dias de estocagem, as demais variáveis, apesar de numericamente muito próximas, mostraram diferenças significativas ao longo do armazenamento por 90 dias.

Comparando-se estatisticamente os resultados das análises físicas e químicas das diferentes formulações para o mesmo período, constatou-se que, logo após o processamento, somente o teor de umidade não apresentou diferença significativa entre as formulações com 35 e $50 \%$ de açúcar mascavo. Após 30 dias de estocagem, o pH, sólidos solúveis, acidez, umidade e açúcar não redutor não apresentaram diferença significativa entre as formulações com 35 e $50 \%$ de açúcar mascavo, no mesmo período, não diferiu significativamente o teor de açúcares totais e de acidez entre as formulações com 50 e $65 \%$ de açúcar mascavo. Após 60 dias de estocagem, o pH, sólidos solúveis e acidez não apresentaram diferença significativa entre as formulação com 35 e $50 \%$ de açúcar mascavo. Após 90 dias de estocagem, o pH, umidade e açúcar não redutor não apresentaram diferença significativa entre as formulação com 35 e $50 \%$ de açúcar mascavo, no mesmo período o teor de açúcares totais não diferiu significativamente entre as formulações com 50 e $65 \%$ de açúcar mascavo. No entanto, a maior parte das comparações evidenciou a existência de diferenças significativas entre as formulações.

A partir dos resultados das análises microbiológicas nas geleiadas de maçã (Tabela 4), pode-se constatar que a incidência e o crescimento de microrganismos do grupo coliforme e de mofos e leveduras foi sempre inferior a $3 \mathrm{NM}^{-1}$ e $30 \mathrm{UFCg}^{-}$ ${ }^{1}$, respectivamente.

Os produtos apresentaram-se de acordo com os padrões definidos pelas Normas Técnicas Especiais e Relativas a Alimentos e Bebidas anexas ao decreto no 12.486 de 30 de outubro de 1978. Esse fato deve-se à qualidade da matéria-prima utilizada, às altas temperaturas empregadas no tratamento térmico, e também à elevada concentração de sólidos solúveis existentes nas geleiadas, o que auxilia na preservação desses produtos. 
Tabela 3 - Características físicas e químicas das geleiadas de maçã elaboradas com diferentes concentrações de açúcar mascavo, após o processamento e durante o armazenamento (90 dias).

\begin{tabular}{|c|c|c|c|c|c|c|c|c|c|c|c|c|}
\hline \multirow[b]{3}{*}{ Dias } & \multicolumn{12}{|c|}{ \% de açúcar mascavo na geleiada de maçã* } \\
\hline & \multicolumn{4}{|c|}{35} & \multicolumn{4}{|c|}{50} & \multicolumn{4}{|c|}{65} \\
\hline & 0 & 30 & 60 & 90 & 0 & 30 & 60 & 90 & 0 & 30 & 60 & 90 \\
\hline \multicolumn{13}{|l|}{ Determinações } \\
\hline $\mathrm{pH}$ & $3,70 \mathrm{aA}$ & $3,75 \mathrm{bA}$ & $3,75 \mathrm{bA}$ & $3,73 \mathrm{bA}$ & $3,79 \mathrm{aB}$ & $3,80 \mathrm{aA}$ & $3,80 \mathrm{aA}$ & $3,81 \mathrm{aA}$ & $3,97 \mathrm{aC}$ & $4,00 \mathrm{aB}$ & $4,01 \mathrm{aB}$ & $4,00 \mathrm{aB}$ \\
\hline $\begin{array}{l}\text { Sólidos solúveis } \\
\text { ( }{ }^{\circ} \text { Brix) }\end{array}$ & 66,6 aA & 67,0 bA & $67,2 \mathrm{cA}$ & 67,0 bA & $66,8 \mathrm{aB}$ & $67,0 \quad \mathrm{bA}$ & $67,0 \quad \mathrm{bA}$ & $66,8 \mathrm{aB}$ & $65,2 \mathrm{aC}$ & $66,0 \mathrm{bB}$ & $66,0 \mathrm{bB}$ & $65,4 \mathrm{cC}$ \\
\hline $\begin{array}{l}\text { Acidez } \\
\text { (\% de ác. cítrico) }\end{array}$ & $0,99 \mathrm{aA}$ & $1,08 \mathrm{aA}$ & $1,00 \mathrm{aA}$ & $0,99 \mathrm{aA}$ & $0,93 \mathrm{aB}$ & $1,08 \mathrm{bA}$ & $1,06 \mathrm{bA}$ & $0,95 \mathrm{aB}$ & $0,72 \mathrm{aC}$ & $1,03 \mathrm{bA}$ & $0,79 \mathrm{aB}$ & $0,76 \mathrm{aC}$ \\
\hline Umidade $(\%)$ & 32,1 aA & 31,8 abA & 31,9 aA & 31,4 bA & 32,7 acA & 31,6 bA & $32,7 \quad \mathrm{cB}$ & 31,9 abA & $34,4 \mathrm{aB}$ & $32,7 \mathrm{bB}$ & $34,2 \mathrm{aC}$ & $33,2 \mathrm{bB}$ \\
\hline $\begin{array}{l}\text { Açúcar total } \\
\text { (\% glicose) }\end{array}$ & 58,1 aA & 60,9 bA & 58,6 aA & $56,0 \mathrm{dA}$ & $61,3 \mathrm{aB}$ & $62,0 \mathrm{aB}$ & 59,8 bB & $59,05 \mathrm{cB}$ & $63,0 \mathrm{aC}$ & $61,8 \mathrm{bB}$ & $59,0 \mathrm{cA}$ & $59,6 \mathrm{~dB}$ \\
\hline $\begin{array}{l}\text { Açúcar redutor } \\
\text { (\% glicose) }\end{array}$ & $21,1 \mathrm{aA}$ & $22,7 \quad b A$ & $20,4 \quad \mathrm{cA}$ & $21,8 \mathrm{dA}$ & $22,6 \mathrm{aB}$ & $24,1 \quad b B$ & $23,0 \quad \mathrm{cB}$ & $23,8 \mathrm{bB}$ & $18,9 \mathrm{aC}$ & $19,4 \mathrm{aC}$ & $19,0 \mathrm{aC}$ & $19,3 \mathrm{aC}$ \\
\hline $\begin{array}{l}\text { Açúcar não-red. } \\
\text { (\% sacarose) }\end{array}$ & 35,1 aA & $36,3 \mathrm{aA}$ & 36,3 aA & $32,5 \mathrm{bA}$ & $36,9 \mathrm{aB}$ & 36,0 bA & $35,0 \quad \mathrm{cB}$ & $33,5 \mathrm{dA}$ & $41,6 \mathrm{aC}$ & $40,2 \mathrm{bB}$ & $37,9 \mathrm{cC}$ & $38,3 \mathrm{cB}$ \\
\hline
\end{tabular}

Letras minúsculas diferentes na mesma linha representam diferença significativa pelo teste de Duncan em nível de 5\% de probabilidade, para o mesmo tratamento durante o tempo de estocagem.

Letras maiúsculas diferentes na mesma linha representam diferença significativa pelo teste de Duncan em nível de $5 \%$ de probabilidade, entre os diferentes tratamentos no mesmo período de estocagem

\section{CONCLUSÕES}

- As geleiadas elaboradas com 35, 50 e $65 \%$ de açúcar mascavo foram, estatisticamente, igualmente preferidas pelos julgadores, superando aquela com $20 \%$;

- considerando o custo e o rendimento, verificou-se que a geleiada com $65 \%$ de açúcar mascavo apresentou vantagem sobre as demais;

- as geleiadas de maçã elaboradas com açúcar mascavo permaneceram dentro dos padrões em relação às suas características físicas, químicas e microbiológicas pelo período de noventa dias de armazenamento à temperatura ambiente;

- as formulações de geleiadas elaboradas com 35, 50 e $65 \%$ de açúcar mascavo apresentaram ao longo do armazenamento diferenças significativas entre si, em relação a suas caraterísticas físicas e químicas.

Tabela 4 - Características microbiológicas das geleiadas de maçã elaboradas com diferentes concentrações de açúcar mascavo durante o armazenamento.

\begin{tabular}{|c|c|c|c|c|c|c|c|c|c|c|c|c|}
\hline \multirow[b]{3}{*}{ Dias } & \multicolumn{12}{|c|}{ \% de Açúcar mascavo nas geleiadas de maçã } \\
\hline & \multicolumn{4}{|c|}{35} & \multicolumn{4}{|c|}{50} & \multicolumn{4}{|c|}{65} \\
\hline & 0 & 30 & 60 & 90 & 0 & 30 & 60 & 90 & 0 & 30 & 60 & 90 \\
\hline \multicolumn{13}{|l|}{ Determinações } \\
\hline $\begin{array}{l}\text { Mofos e Leveduras } \\
\text { UFC. } \mathrm{g}^{-1}\end{array}$ & $<30$ & $<30$ & $<30$ & $<30$ & $<30$ & $<30$ & $<30$ & $<30$ & $<30$ & $<30$ & $<30$ & $<30$ \\
\hline $\begin{array}{l}\text { Coliformes Totais } \\
\text { NMP.g } \mathrm{g}^{-1}\end{array}$ & $<3$ & $<3$ & $<3$ & $<3$ & $<3$ & $<3$ & $<3$ & $<3$ & $<3$ & $<3$ & $<3$ & $<3$ \\
\hline
\end{tabular}

\section{REFERÊNCIAS BIBLIOGRÁFICAS}

ALBUQUERQUE, J.P. Fatores que influem no processamento de geléias e geleiadas de frutas. Boletim da Sociedade Brasileira de Ciência e Tecnologia de Alimentos, Campinas, v.31, n.1, p.62-67, 1997.

BONTEMPO, M. Relatório Orion. Denúncia médica sobre os perigos dos alimentos industrializados: agrotóxicos. Porto Alegre : L\&PM, 1985. 151p.

CHARLEY, H. Food science. 2 ed. New York : John Wiley, 1982. 564p.

COMISSÃO NACIONAL DE NORMAS E PADRÕES DE ALIMENTOS. Normas técnicas especiais. Resolução $\mathrm{n}^{\mathrm{o}}$ 12/33. [Brasil]: D.O.U., 1978. Seção I, pt. I.

FDA. Bacteriological analytical manual for foods Whashington: USDHEW, 1992. App.3.85.

FONSECA,G.D.F. Caracterização de geleiada de maçã elaborada com açúcar mascavo. Pelotas, 1999. 29p. (Trabalho Científico de Estágio) Curso de Ciências Domésticas Universidade Federal de Pelotas, 1999.

GOULARTE,V.D.S. Desidratação da cultivar de maçã Fuji através da pré - desidratação osmótica - efeito das soluções químicas nas características do produto final. Pelotas-RS. 96p. (Trabalho Científico de Estágio) - Curso de Ciências Domésticas, Universidade Federal de Pelotas, 1996. 
INSTITUTO BRASILEIRO DE GEOGRAFIA E ESTATÍSTICA-IBGE. Estudo nacional da despesa familiar. Tabelas de composição dos alimentos. Rio de Janeiro : Fundação IBGE, 1976. 172p.

INSTITUTO ADOLFO LUTZ. Normas analíticas do Instituto Adolfo Lutz: métodos químicos e físicos para análise de alimentos. 2 ed. São Paulo : O Instituto, 1985. 371p.

JACKIX, M.H. Doces, geléias e frutas em calda. Campinas : Ícone, 1988. 172p.

NEVES, N.M. de A. Indústrias caseiras: alimentares - não alimentares. 2 ed. Pelotas : UFPEL, 1990. 163p.

REIS, F.M. Tecnologia dos produtos agro - alimentares. Lisboa : LCE, 1982. 238p. (Coleção Técnica Agrária).
RODRIGUES, R.S., GALLI, D.C., MACHADO, M.R.G. Comparação entre seis marcas de açúcar mascavo. In: CONGRESO LATINOAMERICANO DE INGENIERÍA RURAL, 2, 1998, La Plata; CONGRESO ARGENTINO DE INGENIERÍA RURAL, 5, 1998, La Plata. Anais.... La Plata: CLIR-CADIR, 1998. CD-Rom.

SENAI-RS. Alimentação. Fabricação de geléias e geleiadas. Porto Alegre: SENA̧I, 1990. 61p.

SPEARS, E.E., KASSOUF, A.L. A segurança dos alimentos: uma preocupação crescente. Revista Higiene Alimentar. v.10, n.44, p.18-19. 1996.

STONE, H., SIDEL, J.L. Sensory evaluation practices. 2 ed. Florida : Academic, 1993. 338p.

VETTORAZZI, G., MACDONALD, I. Sacarose - aspectos nutricionais e de segurança no uso do açúcar. São Paulo: Hucitec, 1989. 226p.

Ciência Rural, v. 30, n. 6, 2000. 